Send your letters to the Editor,

British Dental Journal,

64 Wimpole Street

London

W1G 8YS

Email bdj@bda.org

Priority will be given to letters less than 500 words long.

Authors must sign the letter, which

may be edited for reasons of space.

\section{MANAGING EMERGENCIES}

Sir, I was interested in the observations by Shelley et al. (BDJ 2009; 206: 449) on the management of potential airway obstruction in the dental surgery.

The authors are right to raise concerns, but not about the ability to treat emergencies such as the sublingual haematoma. Their concerns should be directed at the inability to recognise and arrange appropriate management of such patients. This includes diagnosing the problem and seeking help from the most appropriate source in a timely manner.

Intubation in the conscious patient requires the use of muscle relaxants and, in the event of developing obstruction, can be challenging even for anaesthetists with extensive experience. It would be inappropriate for a practitioner to attempt to intubate in the circumstances described. What will the practitioner do with a paralysed patient after a failed intubation? Perhaps ring his or her defence organisation.

In the example of a developing sublingual haematoma an urgent phone call to the local Maxillofacial or ENT Unit is probably the best way to get the patient seen and treated quickly. Attempts to treat the condition in the surgery will delay definitive treatment and may result in a sub-optimal outcome.

The authors state that the training to manage these emergencies does not seem to exist. This is not true. SHO posts in maxillofacial units do exactly this, they expose the practitioners to patients with compromised health and developing emergencies, the sublingual haematoma being just one of these. In a structured clinical environment they learn how to manage these emergencies and if they

encounter such problems in practice later in their careers they are able to put this training to use.

It is therefore unfortunate that some postgraduate dental deans do not seem to understand how useful the experience gained as an SHO in a hospital post can be, especially as much of this experience is gained when 'on-call'. Some of these deans have publicly stated that they do not want 'dental' SHOs to be on call as it has no relevance to general dental practice. I beg to differ. Perhaps a period of time spent in an on-call post should be a compulsory part of the proposed 'F2' year in order to ensure all graduates have exposure to the management of patients with potentially life threatening emergencies.

P. Ramsay-Baggs

By email

DOI: 10.1038/sj.bdj.2009.768

\section{IGNORED REPORT}

Sir, when I left office as the chairman of the General Dental Services Committee (GDSC) in January 2003 I resolved not to make public utterances in the future on matters relating to the General Dental Services.

However, I cannot let your report of the Westminster Health Forum keynote seminar entitled 'The Future of Dentistry" pass without comment - in particular the conclusions of Professor Watt.

You reported that he said '...there was no perfect system of the remuneration of dentists ... around the world different systems have been tried, no system will be satisfactory to the three stakeholders, the public, the profession or the government'. He called for tests and pilots of different models of care, stating that one system would not fit all.
In August 2002 the Department of Health (DoH) published 'NHS dentistry: options for change.2 This report, accepted by the then Secretary of State, was the result of months of discussions and debates between all the principal stakeholders (including the DoH and the GDSC), ably chaired by Dame Margaret Seward, the then Chief Dental Officer for England. The report embraced the conclusions of three task groups.

One of these task groups examined 'Systems of delivery of dental care'. Amongst their conclusions was 'No one system of remuneration suits everybody, practices and patients are different and there must be some accommodation for this in any new system'. The task group was chaired by Dr Barry Cockcroft, who is the current Chief Dental Officer for England.

The respective governments chose to ignore their own report when introducing the April 2006 contract in England and Wales.

\section{A. S. Kravitz OBE} London

1. Dentistry's future debated. Br Dent J 2009; 206: 565.

2. Department of Health. NHS dentistry: options for change. London: Department of Health, 2002

DOI: 10.1038/sj.bdj.2009.769

\section{UNUSUAL GINGIVITIS}

Sir, as per the photograph enclosed (Fig. 1), I am writing this letter to bring this unusual form of gingivitis to the attention of our colleagues. I have only seen this condition twice in this form and I have not seen it written up in the literature or any specific reference to it. In the absence of any other name for it I refer to it as post-cancer lichenoid gingivitis. The two cases that I have seen had the following characteristics: 
- Post-menopausal females (both patients)

- Breast cancer (one full single mastectomy, the other partial single mastectomy)

- Clearance of local lymph nodes (one case and not the other)

- Post-surgical chemotherapy (both patients)

- Post-surgical radiotherapy (in one case but not the other)

- Concurrent hormone replacement therapy (Fosamax: one case and not the other).

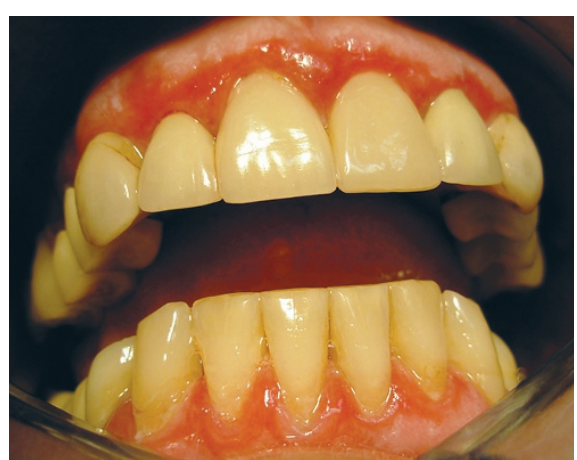

Fig. 1 Post-cancer lichenoid gingivitis

The clinical features of the oral condition present as a characteristic painless marginal atrophic gingivitis with a straight and clearly defined demarcation line about 2-3 $\mathrm{mm}$ from the gingival margin. Other red patches are sometimes seen in the mucosa adjacent to the molar regions, reminiscent of physical trauma during function. Characteristically there are no Whickham's striae or other white lines/areas or other bullous lesions present either intraorally or extra-orally. On close questioning one of these patients described a skin rash which presented as crops of ulcers 1-3 mm in diameter on her forearms. She could not recall these ulcers being preceded with blisters prior to forming.

In both cases the condition seemed to fade with time, taking approximately 18 months to disappear completely.

Management has included reassurance that it was not a new manifestation of the original cancer, regular reviews including palpating the head and neck regions for enlarged lymph nodes and checking intra-orally for any abnormalities in the soft tissues or any asymmetric enlargements of the peri-oral bone.
While one of the patients was taking a Fosamax (alendronate)-based tablet (an anti-osteoporosis bisphosphonate drug), and these are known to create a variety of side effects including urticaria and rashes, the other patient was not taking this medication and developed similar oral lesions. I have therefore concluded that this condition arises from some aspect of the cancer treatment that both of these ladies had received rather than being due to this medication.

I look forward to receiving comments from other colleagues who may have observed similar lesions and their views on what the causative agents may be.

P. Galgut

London

DOI: 10.1038/sj.bdj.2009.770

\section{HOOKAH EPIDEMIC}

Sir, I would like to add some further useful references to Drs Dar-Odeh and Abu-Hammad's interesting paper on narghile (hookah, shisha) smoking. ${ }^{1}$ For instance, Indian cancer specialists have earlier noted that the South-East Asian water pipe 'does not appear to produce precancerous oral lesions'. ${ }^{2}$ Regarding smokeless tobacco, the important fact that tobacco smoking and chewing act synergistically is indeed noteworthy. ${ }^{3}$ Also, an impressive study about leukoplakia showed that hookah smoking 'did not lead to any appreciable number of lesions, because neither the smoke nor the pipe are too warm'.

As for the study on bronchogenic carcinoma, $^{5}$ not only were 14 of the 17 smokers heavy users ( $>110 \mathrm{~g}$, ie the weight equivalent of 110 cigarettes) and the hygienic conditions unknown but also in the same region, Jindal et al. showed that almost one third of all patients with bronchogenic carcinoma and $94.4 \%$ of the 54 women had never smoked. ${ }^{6}$ Pollution, kerosene, and even radon are important. In fact, about two dozen publications point in the other direction, including the first aetiological study ever carried out on this issue with exclusive/ever hookah smokers. ${ }^{7}$ As for the other scarcely reported cases of other types of cancer (oesophageal, bladder, pancreatic) and other diseases (contact eczema, tuberculosis or aspergillosis, etc), the attention was often drawn to a non-rigorous methodology (simultaneous use of other products eg qât, cigarettes, bidis, pan, etc; strongly neglected hygiene; unclear current profile and past smoking career). ${ }^{8}$ This applies to the few cases of oral squamous cell carcinoma studied by El-Hakim et al. who, surprisingly, also mention 'the heat generated from the smoke' and the 'irritation by tobacco juice products.. ${ }^{9}$ This is not possible because the inhaled hookah smoke temperature is below that of the ambient air and, unlike a cigarette, pipe or cigar, no 'tobacco juice' can reach the smoker's mouth further to a trip of up to 200 to $300 \mathrm{~cm}$ on average (not to mention the bath).

Dar-Odeh and Abu-Hammad ${ }^{1}$ warn against the great amount of 'tar'. However, cigarette 'tar' and hookah tar are completely different. Narghile smoke is mainly made up of water and glycerol (no biological activity) and is far less concentrated in chemicals (hundreds vs thousands) than cigarette smoke. ${ }^{8}$ As for the great amounts of aldehydes and polycyclic aromatic hydrocarbons, these are not those of human 'smoking sessions' but those artificially produced by an unrealistic narghile smoking machine (one puff every $17 \mathrm{~s}$ for a full hour...) supposed to mimic the average narghile smoker. Amazingly, the only hot debate has been about the international standard smoking machine for cigarettes which draws only but a few puffs every 60 s. Hookah smoking machines set with different parameters revealed completely different toxicant yields. ${ }^{8,10-12}$ As a conclusion, the main clearly and early identified public health problem is carbon monoxide. ${ }^{8,13}$ Unfortunately, tobacco harm reduction policies are still taboo so the hookah epidemic has been worsening for a decade now. ${ }^{14}$

K. Chaouachi

By email

1. Dar-Odeh N S, Abu-Hammad O A. Narghile smoking and its adverse health consequences: a literature review. Br Dent J 2009; 206: 571-573.

2. Pindborg J J, Murti P R, Bhonsle R B, Gupta P C. Global aspects of tobacco use and its implications for oral health. In Gupta P C, Hamner J E, Murti P R (eds). Control of tobacco-related cancers and other diseases. International Symposium, 1990. Bombay: Oxford University Press, 1992.

3. Jayant K, Balakrishnan V, Sanghvi L D, Jussawalla D J. Quantification of the role of smoking and chewing tobacco in oral, pharyngeal, and oesophageal cancers. Br J Cancer 1977; 35: 232-235. 
4. Mehta F S, Pindborg J J, Gupta P C, Daftary D K Epidemiologic and historic study of oral cancer and leukoplakia among 50,915 villagers in India. Cancer 1969; 24: 832-849.

5. Nafae A, Misra S P, Dhar S N, Shah S N. Bronchogenic carcinoma in Kashmir Valley. Indian J Chest Dis 1973: 15: 285-295

6. Jindal S K, Malik S K, Dhand R, Gujral J S et al Bronchogenic carcinoma in Northern India. Thorax 1982; 37: 343-347.

7. Sajid K M, Chaouachi K, Mahmood R. Hookah smoking and cancer. Carcinoembryonic Antigen (CEA) levels in exclusive/ever hookah smokers. Harm Reduct J 2008; 19.

8. Chaouachi K. Hookah (shisha, narghile) smoking and environmental tobacco smoke (ets). A critica review of the relevant literature and the public health consequences. Int J Environ Res Public Health 2009; 6: 798-843.

9. El-Hakim I E, Uthman M A E. Squamous cel carcinoma and keratoacanthoma of the lower lip associated with 'goza' and 'shisha' smoking. Int J Dermato/ 1999; 38: 108-110.

10. Chaouachi K. Public health intervention about narghile (hookah, shisha) entails a radical critique of the related 'standardised' smoking machine. J Public Health 2009; in press.

11. Rakower J, Fatal B. Study of narghile smoking in relation to cancer of the lung. Br J Cancer 1962 16: 1-6.

12. Sanghvi L D. Cancer epidemiology: the Indian scene. J Cancer Res Clin Oncol 1981; 99: 1-14.

13. Salameh P, Aoun Bacha Z, Waked M. Saliva cotinine and exhaled carbon monoxide in real life waterpipe smokers: a post hoc analysis. Tobacco Use Insights 2009; 2: 1-10.

14. Chaouachi K. Harm reduction techniques for hookah (shisha, narghile, 'water pipe') smoking of tobacco based products. Med Hypotheses 2009; in press.

DOI: 10.1038/sj.bdj.2009.771

\section{OIL THERAPY}

Sir, I would like to share with your readers the concept of 'oil pulling' which is regularly performed in the southern part of India. It is an ancient Ayurvedic procedure in which a tablespoon of oil (preferably sunflower or sesame or other cold pressed refined oil) is rinsed or swished around the mouth, pulling it through the teeth. This procedure is carried out for about 15 to 20 minutes until the oil gets thinner and turns white in colour. The oil is then spat from the mouth and the mouth is thoroughly rinsed with warm water or tap water and cleaned with the fingers. People perform this procedure saying that it is a good exercise for oral musculature, reduces tooth pain, secures mobile teeth and eliminates bleeding gums. The literature has reported that it has been also used to effectively treat various disorders like bronchitis, eczema, migraine headaches, nerve paralysis, arthritis, blood disorders, gastroenteritis, peritonitis, meningitis, heart and kidney disorders, women's hormonal disorders, and chronic diseases like cancer, AIDS etc.
The exact mechanism of the effectiveness of this procedure is not known, but it is said that it heals cells, tissue and all organs simultaneously. It activates the enzymes of the body and these enzymes draw toxins out of the blood. Also, during the swishing of the oil, the person's metabolism is intensified. In India, people perform this procedure early in the morning with an empty stomach. I feel that further research is warranted to know exactly how this procedure works in the case of odontogenic problems.

\section{Ballal} Manipal DOI: 10.1038/sj.bdj.2009.772

\section{WORK COHESIVELY}

Sir, in response to the letter from L. C. Hampshire entitled Set up to fail (BDJ 2009; 206: 507-508) I would like to highlight the following.

The National Examining Board for Dental Nurses (NEBDN) has a robust Quality Assurance process in place whereby only training centres accredited by NEBDN can offer training. Although this ensures a standardised approach to the delivery of the training programme, it would be unrealistic to include selection criteria as part of the accreditation process. Educational providers should be responsible for accepting students on their courses, and many would resent interference from external agencies such as NEBDN.

Education providers do 'take on' the students when they accept them on to the course. They have a responsibility to provide training of an adequate standard for students in preparation for examinations. NEBDN accreditation is an important indicator that a range of quality measures are in place, but courses will not be identical. As there is no strong evidence that previous academic qualifications are a reliable indicator of an ability to learn, course leaders should be able to use their own judgement and ensure that students will be competent to sit the examination.

NEBDN agrees wholeheartedly that employers should consider a trainee dental nurse's educational needs when recruiting. With mandatory registration, such oversight is likely to become more uncommon as employers will have a constant problem unless they are able to recruit dental nurses capable of qualification.

Education providers should endeavour to overcome problems of lack of employer support through a learning agreement which all three parties commit to prior to commencement of the course. It is important that the dental profession works cohesively to ensure that we have highly trained, highly able dental nurses.

P. Hughes

Chief Executive, NEBDN

DOI: $10.1038 /$ sj.bdj.2009.773

\section{HUMILIATION}

Sir, I have just had the humiliating experience of applying for registration under the Private Dentistry Wales Regulations. Not only was I subjected to a criminal record check, I also had to provide two referees who could vouch for my clinical competence. Thirty years of NHS service apparently counted for nothing. I wasn't even trusted to give my own name and address but had to submit proof in the form of a birth certificate, domestic utility bill and verified passport photograph.

If the Government really wants to improve the standard of private dentistry it should encourage and support dental professionals rather than abuse and demean them.

G. E. Swan

Rhondda Cynon Taff DOI: 10.1038/sj.bdj.2009.774

\section{RIGHTS REGAINED}

Sir, may I via the courtesy of your columns express my thanks to the numerous friends and colleagues who responded to my recent letter in which I outlined the anomalous and restrictive measures that had been imposed on dentists who need to order prescription only medicines in emergency.

It is with pleasure that I write to inform my fellow dentists that as a result of our efforts we have now regained our former rights of prescription. None of the bodies mentioned in my original letter communicated with me to show their acknowledgement of responsibility but as we have regained our rights we must be content with the outcome.

M. B. Rothschild

London

DOI: $10.1038 /$ sj.bdj.2009.775 


\section{X-RAY BURN OUT}

Sir, with reference to the article The mesio-angular third molar - to extract or not to extract (BDJ 2009; 206: E23), I do thank R. T. Allen et al. for their extremely helpful paper which certainly refines established NICE guidance.

There is, however, that phenomenon of X-ray 'burn out', artifactually suggesting distal caries in the second molar. This paper does not differentiate between such a possibility and an actual second molar cavity. Perhaps a second clinical/radiographic examination following wisdom tooth removal to determine 'burn out', arrested caries or a frank cavity requiring restoration, would further 'fine tune' the NICE Guidelines.

B. Littler Chelmsford DOI: 10.1038/sj.bdj.2009.776

\section{DENTAL DECISIONS}

Sir, we read with interest the letter Another hiccup by S. Laverick of Dundee (BDJ 2009; 206: 509), a consultant oral and maxillofacial surgeon, with reference to having to pay registration fees to both the GDC and GMC. Given that oral and maxillofacial surgery includes some aspects of dentistry and that only registered dentists can carry out the practice of dentistry it follows then that de-registration with the GDC might restrict this practice. For example, it is accepted that removal of a tooth is a maxillofacial procedure, but the decision as to whether a tooth needs removal or can be restored is clearly a dental decision.

Much of the routine day to day care of patients in 'maxfac' units can be delegated to dentally registered junior and middle grade staff, but those individuals work under the authority of a named consultant and unless the consultant is appropriately registered it would be inappropriate for him/her to assume responsibility for those patients; the non-consultant staff would have to act as independent practitioners; this is not in line with current hospital practice where patients are under the care and responsibility of a named consultant. Furthermore, dental care professionals can take prescriptions for treatment only from registered dentists, therefore de-registration from the GDC could limit the range of treatments available in specialist units and also limit employment of DCPs within hospital practice. One can imagine a scenario where a general dental practitioner refers a patient to his/her local hospital only to have the referral returned on the grounds that the consultant cannot accept responsibility for the case; similarly a patient who sustains traumatic injuries may not be able to benefit from temporary restoration of any damaged teeth but could have a fractured mandible reduced and fixed.

If the British Association of Oral and Maxillofacial Surgeons wish to advise their fellows to de-register with the GDC then perhaps they would consider making a case for the appointment of more consultants in oral surgery to care for those patients for whom maxfac consultants could potentially no longer assume responsibility?

I. Brook

C. Freeman

Sheffield

DOI: 10.1038/sj.bdj.2009.777

\section{ACCEPTING RESPONSIBILITY}

Sir, your readers may be interested to know that I have laid a formal complaint with the General Dental Council, because I believe the trustees of the British Orthodontic Society 'are failing to provide the general public with fully informed consent about orthodontic treatment'.

There is no doubt that:

- Most orthodontic treatment increases vertical growth

- Those with vertical growth tend to look less attractive

- Vertical growers tend to develop long-term crowding.

This is not the place for a detailed critique but the specialty must accept responsibility for these and other adverse side effects of modern fixed appliances. Sadly our patients are often quite unaware that they exist.

Lack of informed consent particularly applies to orthognathic surgery where patients are rarely told about alternatives such as 'Natural Growth Guidance' which claim to achieve a full correction without surgery. This is not because orthodontists do not know about them, but because they don't believe they work. This should be for the patient to decide not the orthodontist. Patients waiting for surgery are likely to want any information about non-surgical methods, regardless of their effectiveness.

The General Dental Council takes a stern attitude to any clinician who fails to mention all alternatives 'that the patient might wish to know about'. Currently about half the patients who are offered surgery subsequently have compromise treatment or accept their condition, never knowing that a full correction might have been achieved without surgery.

Because the orthodontists speak with one voice their opinions are often accepted without question, even by august bodies such as the GDC. Over the years I have frequently voiced these concerns and as a result I have been labelled an 'unscientific maverick', my character has been impugned to a point where established figures will not reply to my letters, my efforts to apply logic to orthodontic treatment have been ridiculed and I have now been thrown out of the British Orthodontic Society. I accept all this as the lot of those who challenge the establishment but sometimes it has to be done.

I have many good friends in orthodontics and I hope they will forgive this transgression but the specialty must become more self critical if we are to maintain the public's faith. It is no good saying 'this is as good as it gets'.

$$
\begin{array}{r}
\text { J. Mew } \\
\text { By email } \\
\text { DOI: } 10.1038 / \mathrm{sj.bdj.2009.778}
\end{array}
$$

\section{SLOGAN STANDARDS}

Sir, I very much agree with Dr Marshall's letter (BDJ 2009; 207: 53). The GDC slogan is a bit negative and now out-of-date. Could I suggest something like 'The General Dental Council - Setting the Standards in UK Dental Healthcare, on behalf of all patients'. This would encompass its role in monitoring education and training, CPD, overseas applicants etc as well as disciplinary. The whole dental team supports the GDC financially and we want to live up to its standards.

J. Fenwick

Newport

DOI: 10.1038/sj.bdj.2009.779 